\title{
Numerical analysis of circular and square concrete filled aluminum tubes under axial compression
}

\author{
Pan Jinlong, Li Guanhua, Cai Jingming* \\ Southeast University, China \\ cejlpan@seu.edu.cn, \\ guanbuali1997@gmail.com, bttps:/ /orcid.org/0000-0003-2235-1402 \\ jingming.cai@kuleuven.be,https://orcid.org/0000-0003-2453-582X
}

ABSTRACT. In this paper, the finite element (FE) method was used to
investigate the axial compressive behaviors of circular and square concrete
filled aluminum tubes (CFAT). Firstly, the simulation results were compared
with the experimental results and the accuracy of the proposed FE model was
verified. On this basis, the FE model was further applied to compare the
mechanical properties of both circular and square CFATs under axial
compression. It was found that the circular CFATs have a better effect on
restraining the core concrete than square CFATs. The parametric analysis was
also conducted based on the proposed FE model. It was noticed that the
mechanical differences of the two kinds of CFATs gradually decreased with
the increase of the aluminum ratio, aluminum strength and concrete strength.

KEYwORDS. CFAT; Numerical simulation; Finite element analysis; Parameter analysis.

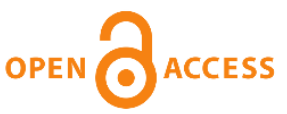

Citation: Jinlong, P., Guanhua, L., Jingming, C., Numerical analysis of circular and square concrete filled aluminum tubes under axial compression, Frattura ed Integrità Strutturale, 54 (2020) 169-181.

Received: 28.05 .2020

Accepted: 24.08 .2020

Published: 01.10.2020

Copyright: (C) 2020 This is an open access article under the terms of the CC-BY 4.0, which permits unrestricted use, distribution, and reproduction in any medium, provided the original author and source are credited.

\section{INTRODUCTION}

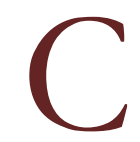

oncrete filled steel tube (CFST) has favorable ductility, high strength and energy dissipation performance because of the constraint effect of steel tube on the core concrete [1]. The aluminum alloy has good corrosion resistance and prominent exterior, which makes the aluminum tube column have been gradually used in the construction of humid and corrosive environment [2,3]. Similar to CFST, concrete filled aluminum tube (CFAT) is expected to have an excellent restraining effect on core concrete. Among the many sections of CFAT, circular section and square section are the most typical. Circular section CFAT has better confinement to the core concrete, while square section CFAT is prone to local buckling. But in some cases, for example, when there are requirements for architectural design, frame joint and section bending stiffness, square CFAT has more advantages.

As a composite structure of aluminum and concrete, CFAT's axial compression performance is worthy of in-depth investigation. In aspect of numerical simulations studies, Zhou and Young [4] studied circular section CFAT short columns loaded axially. In experimental aspect, Zhou and Young [5,6] studied circular, square and rectangular section CFAT short columns under axial loads. These studies revealed that aluminum tubes filled with concrete can remarkably improve axial 
compressive strength of the section and bring better corrosion resistance, while the presence of core concrete can significantly alleviate and delay local buckling of aluminum tubes.

Some experiments and numerical simulations on CFATs' bearing capacity have been carried out. Gardner and Ashraf [7] first put forward the non-linear material model of aluminum alloy materials. On this basis, Wang et al. [8] studied the bearing capacity and stiffness of circular aluminum tube concrete column under axial compression through experiments and numerical simulations. It was concluded that circular CFAT specimen had good bearing capacity and ductility as conventional CFST specimen. Compared with experimental data, general design rule cannot give a good prediction, so Zhou and Young [4,6] put forward a design criterion of square and circular CFAT's bearing capacity under axial compression, as shown in Eq. (1)

$$
P_{P}=A_{a} f_{y}+0.85 A_{c} f_{c}+\eta A_{c} f_{y}
$$

where $P_{P}$ is the proposed strength of CFAT; $A_{a}$ denotes the full cross section area of aluminum tube; $f_{y}$ is $0.2 \%$ proof stress of aluminum; $A_{c}$ is the area of core concrete; $f_{c}$ is the cylinder strength of concrete; $\eta$ is a geometric parameter. Nevertheless, due to the limitation of the scale and conditionality of the CFAT axial compression test, there is no uniform compression standard. There exist mechanical differences between square and circular CFATs, but current researches on the comparison of axial compression performance of circular and square CFATs are very limited.

In this paper, mechanical properties of circular and square CFAT under axial compression were studied by numerical simulation. Compared with the above researches, this research has following improvements:

(1) In order to make the comparison of compression test on two kinds of CFATs more meaningful, this experiment ensured that the material type and material consumption of two CFATs were consistent except for the difference of cross-section geometry. Under this condition, the compression of two CFATs was comparable.

(2) In this study, by comparing the interaction between aluminum tube and core concrete of two CFATs, essential differences of stress mechanism between circular and square CFAT under axial load were revealed.

(3) In the comparison of two kinds of CFATs in whole load-displacement process, it was clearly shown that the behavior of circular and square CFATs under axial load was different.

(4) Three parameters (core concrete strength, aluminum strength and aluminum ratio) were set. On the basis of parameter study, the trend of variation of parameters was analyzed.

The practicability of ABAQUS software was proved, and then the mechanical properties of two kinds of CFATs under axial compression were compared by ABAQUS software. The research in this paper provided a reference for engineering application of CFAT and pointed out ideas for optimization design.

\section{RELIABILITY OF FINITE ELEMENT MODELING}

\section{Constitutive model of aluminum material}

lastic-plastic model was applied to describe constitutive behavior of aluminum. It is assumed that aluminum have isotropic constitutive behavior. Based on the compression concern and extensive usage of aluminum [9,10], it can be specifically described as Ramberg-Osgood formula and its extension, as shown in Eq. (2) and Eq. (3)

$$
\begin{aligned}
& \text { For } \sigma \leq \sigma_{0.2}: \varepsilon=\frac{\sigma}{E_{0}}+0.002\left(\frac{\sigma}{\sigma_{0.2}}\right)^{n} \\
& \text { For } \sigma>\sigma_{0.2}: \varepsilon=\frac{\sigma-\sigma_{0.2}}{E_{0.2}}+\left(0.008-\frac{\sigma_{1.0}-\sigma_{0.2}}{E_{0.2}}\right)\left(\frac{\sigma-\sigma_{0.2}}{\sigma_{1.0}-\sigma_{0.2}}\right)^{i_{0.2 .1 .0}}+\varepsilon_{0.2}
\end{aligned}
$$

where $\varepsilon$ and $\sigma$ represent the strain and stress of aluminum tube, $\sigma_{0.2}$ and $\sigma_{1.0}$ are $0.2 \%$ and $1.0 \%$ proof stress, $\varepsilon_{0.2}$ is the strain at $\sigma_{0.2} . E_{0}$ and $E_{0.2}$ are aluminum materials' Young modulus and tangent stiffness at $\sigma_{0.2}$ respectively. $n_{0.2,1.0}^{\prime}$ is a strain hardening coefficient, representing nonlinearity extent of the stress-strain response, which is taken as 4.5 for T4,

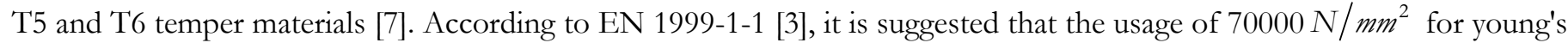


modulus of aluminum and 0.3 for Poisson's ratio is acceptable. Representative material stress-strain graph for aluminum is shown in Fig. 1 (a) in order to see the constitutive relationship more intuitively.

\section{Constitutive model of concrete}

Because of the similarity of the mechanical properties between CFAT core concrete and CFST core concrete [5], the stressstrain model for CFST's core concrete proved by Han et al. [11,12] can be used for concrete of CFAT. Therefore, the core concrete model in CFST was used as core concrete model of CFAT reasonably, as shown in Eq. (4)

$$
m=\left\{\begin{array}{l}
2 n-n^{2}, n \leq 1 \\
\frac{n}{\beta_{0}(n-1)^{\eta}+n}, n>1
\end{array}\right.
$$

where $m=\sigma / f_{c}^{\prime}, n=\varepsilon / \varepsilon_{0} ; f_{c}^{\prime}$ represents concrete cylinder compressive strength; $\varepsilon$ and $\sigma$ denotes the strain and stress of concrete respectively; $\varepsilon_{0}$ is the strain where maximum equivalent of concrete stress is obtained. $\eta=2$ is for circular section, $\eta=1.6+1.5 / n$ is for square and rectangular section. $\beta_{0}$ is a model calculation parameter and it is given in Eq. (5) and Eq. (6)

$$
\begin{aligned}
& \text { For circular CFAT: } \beta_{0}=\left(2.36 \times 10^{-5}\right)^{\left[0.25+(\xi-0.5)^{7}\right]} \times\left(f_{c}^{\prime}\right)^{0.5} \times 0.5 \geq 0.12 \\
& \text { For square CFAT: } \beta_{0}=\frac{\left(f_{c}^{\prime}\right)^{0.1}}{1.2 \sqrt{1+\xi}}
\end{aligned}
$$

where $\xi$ is a confinement factor. According to ACI 318-11 [13], 4730 $\sqrt{f_{c}^{\prime}}$ and 0.2 are recommended for elastic modulus and Poisson's ratio of concrete, respectively. In addition, Representative material stress-strain graphs for concrete are shown in Fig. 1 (b).
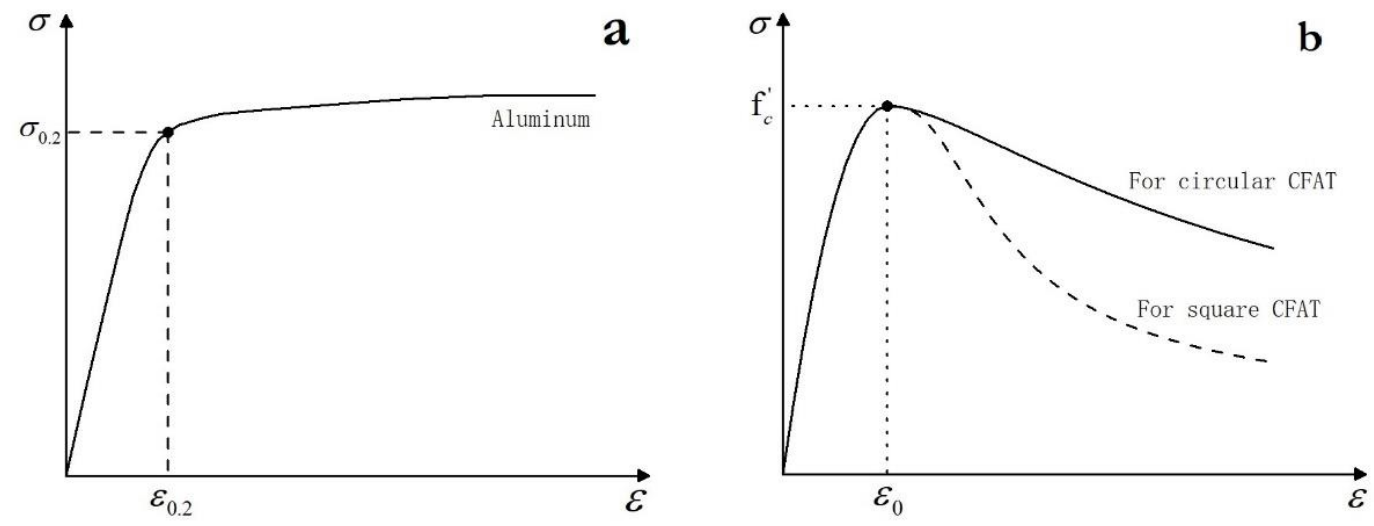

Figure 1: Material stress-strain graphs for CFAT: (a) Representative material stress-strain curve of aluminum; (b) Representative material stress-strain curves of concrete

Element type, boundary condition and loading mode

ABAQUS [14] was selected as the calculation software. Eight-node 3D solid element (C3D8) was used to simulate concrete part, and four-node conventional plate shell element $(\mathrm{S} 4 \mathrm{R})$ was used to simulate aluminum tube. Two rigid elastic blocks with large rigidity were used to simulate the plates at both ends, which had negligible deformation. "Hard contact" was chosen for the contact relation between end-plates and concrete part, while "Tie" was chosen for the contact relation between end-plates and aluminum tube. In this way, both displacements and rotation angles of contact elements were guaranteed to be the same. As it's known to us, there is no contact pressure between aluminum tube and concrete unless one surface contacts the other. In order to simulate this characteristic, "hard contact" was also used in the normal direction 
of contact surfaces between aluminum tube and core concrete, which allowed contact surfaces to separate from each other after contact. Schneider [15] took 0.25 for friction coefficient of the contact surfaces. Because of the slight effect of bonding between aluminum tube and core concrete and inadequate testing on these mechanical properties, 0.25 was taken as friction coefficient for CFATs in consideration of smoother contact surface between aluminum tube and concrete.

\section{Verification of the finite element model}

Zhou et al. [5,6] studied axial compression performance of circular and square CFATs. Through their experiments of several specimens, the influence of aluminum tube shape, wall thickness and concrete strength on CFAT's ultimate strength was been studied. Material properties of aluminum tube specimens in Zhou and Young's tests were determined by tensile coupon tests according to American Society for Testing and Materials Standard [16], which requests tensile tests in a displacementcontrolled MTS (machinal tractor station) testing machine using friction grips. Material properties of concrete in their tests were determined by standard cylinder tests. The concrete cylinder dimensions and test procedure conformed to the American Specification [17]. Because the mean value of their measured concrete strength had a relatively small coefficient of variation (COV), The number of specimens per tested column type is one in Zhou and Young's tests [5,6].

\begin{tabular}{cccccccc}
\hline $\begin{array}{c}\text { Label of } \\
\text { specimen }\end{array}$ & $\mathrm{D}(\mathrm{mm})$ & $\mathrm{T}(\mathrm{mm})$ & $\sigma_{0.2}(\mathrm{MPa})$ & $\sigma_{u}(\mathrm{MPa})$ & $E_{0}(\mathrm{GPa})$ & $f_{c}^{\prime}(\mathrm{MPa})$ & $E_{\mathrm{c}}(\mathrm{GPa})$ \\
$\mathrm{C} 1$ & 150.1 & 2.53 & 267.9 & 282.9 & 64.9 & 44.8 & 31.7 \\
$\mathrm{C} 2$ & 50.0 & 3.13 & 238.4 & 259.1 & 66.1 & 44.8 & 39.6 \\
$\mathrm{~S} 1$ & $88.0 \times 88.0$ & 1.76 & 246 & 263 & 67.3 & 108.6 & 49.3 \\
$\mathrm{~S} 2$ & $100 \times 44.1$ & 1.57 & 263 & 284 & 68.1 & 74.4 & 40.8 \\
\hline
\end{tabular}

Table 1: Specimen parameters (D: Diameter or length, T: Thickness of the aluminum tube, $\sigma_{0.2}: 0.2 \%$ proof stress of aluminum, $\sigma_{u}$ : tensile strength of aluminum, $E_{0}$ : Initial Young's modulus of aluminum, $f_{c}^{\prime}$ : Compressive strength of concrete, $E_{\mathrm{c}}$ : Young's modulus of concrete).

In this study, experimental values of the specimens (C1, C2, S1 and S2; "C" stands for circular CFAT, "S" stands for square CFAT) were compared with simulated results, therefore, finite element model could be verified. Detailed parameters of four groups of test pieces are given in Tab. 1. The comparison between calculated load-displacement (L-D) curves and experimental results is shown in Fig. 2 and Fig. 3. It was found that the maximum error between simulation data and experimental values can be controlled within $8.5 \%$, and simulation values were relatively smooth. On the whole, the simulation values attain a good agreement with the outcome of experiments.

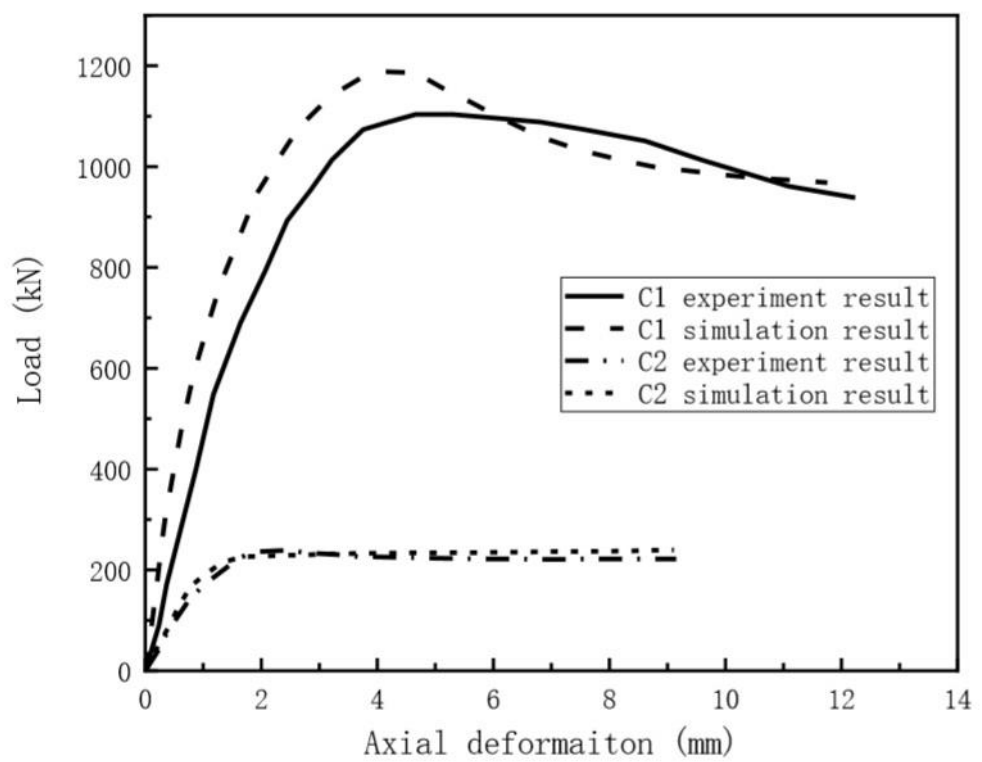

Figure 2: The experimental and simulation L-D curves of circular CFAT. 


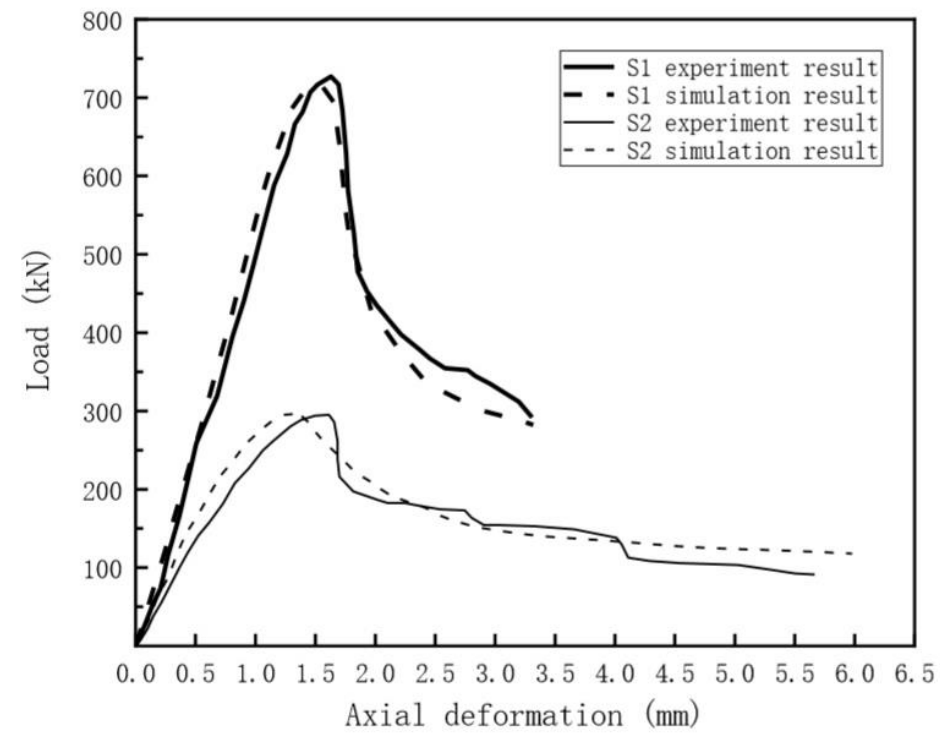

Figure 3: The experimental and simulation L-D curves of square CFAT.

\section{COMPARATIVE STUDY}

$\mathrm{I}$ n the comparative study, two kinds of CFATs were designed, as shown in Fig. 4. It was shown that these two CFAT columns were rigorously the same except for geometric difference by simple calculating. According to GB50010-2010 [18], C30 was set for concrete and nominal value of concrete cube compressive strength can be read from grade of concrete, for example, the following notation "C 30 " and "C40" indicate the cube strength (MPa) with 95\% guarantee rate measured after curing to 28 days under standard curing conditions (temperature around $20{ }^{\circ} \mathrm{C}$, relative humidity above $95 \%$ ), where "C 30 " indicates $30 \mathrm{MPa}$, and "C 40 ” indicates $40 \mathrm{MPa}$. The elastic modulus could be calculated by $4730 \sqrt{f_{c}^{\prime}}$ ., which was described above. What's more, a common kind of aluminum alloy 6063/T6 was used for the tube. The material composition of circular and square CFAT was the same, and both circular and square CFAT were $800 \mathrm{~mm}$ high.

\section{Typical failure model}

After calculation and post-processing by ABAQUS software, the failure modes of circular CFAT and square CFAT under axial compression are shown in Fig. 5. It is clearly found that circular CFAT changed into drum-like shape, that is, the middle of circular CFAT is thicker than both ends of column, and local buckling was not be discovered; while square CFAT not only have local buckling at the two ends near the plates, but also expand in the middle part apparently. The middle section of circular CFAT and square CFAT damaged by axial compression are shown in Fig. 6. It is obvious that the core concrete area of circular CFAT is in close contact with aluminum tube. However, the core concrete of square CFAT only keeps contact with aluminum tube at four corners and the separation of core concrete and aluminum tube occurs in other position.

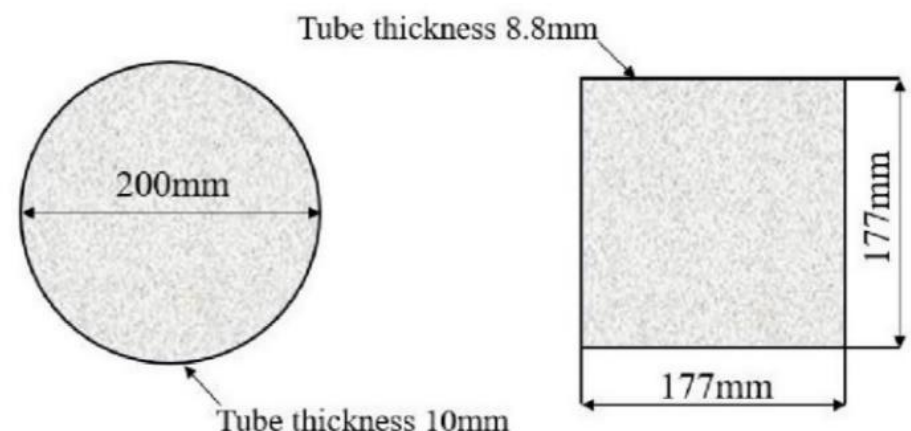

Figure 4: Design dimension of cross section for circular and square CFAT. 


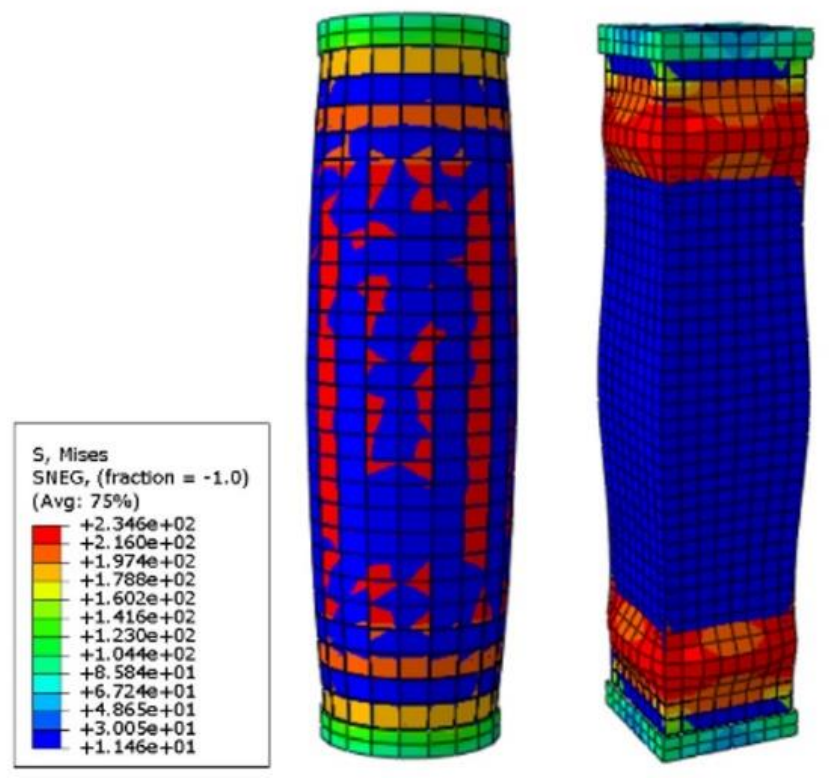

Figure 5: Failure model of circular and square CFST under axial compression
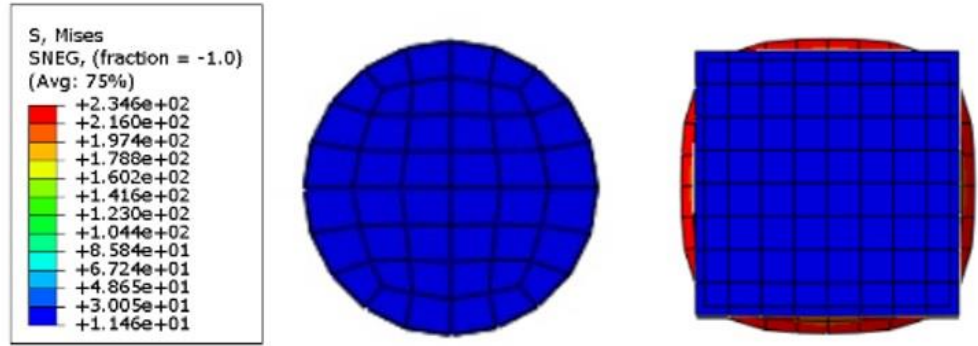

Figure 6: Middle section of circlar and square CFAT damaged by compression

Interaction characteristics between aluminum tube and core concrete

As shown in Fig. 7, three different points were selected for the core concrete of circular CFAT, which named A, B and C. Similarly, three different points were for square CFAT, namely A', B' and $\mathrm{C}^{\prime}$. It is worth noting that these six points are located in or near the middle of each CFAT. Since it was interesting in the stress state at the local buckling of square aluminum tube, D' point was added to the local buckling. In addition, circular CFAT had no local buckling in aluminum tube, so there was no such $\mathrm{D}$ point corresponding to it.
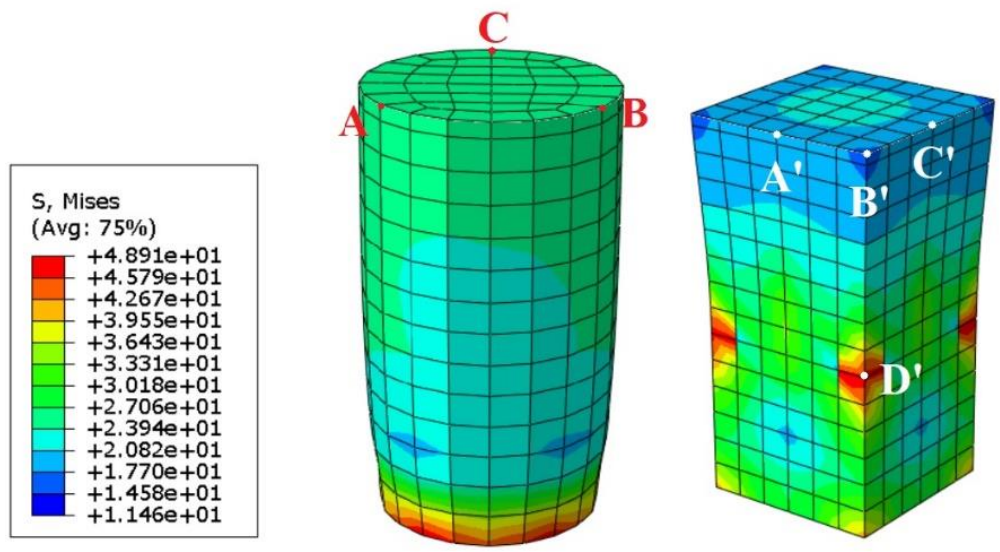

Figure 7: Point location of each CFAT's core concrete 
The contact stresses at these six points are shown in Fig. 8. The performances of contact stresses in point $\mathrm{A}, \mathrm{B}$ and $\mathrm{C}$ were almost the same. It was found that the smooth curves of $\mathrm{A}, \mathrm{B}$ and $\mathrm{C}$ was zero at the initial stage until the axial deformation was about $5 \mathrm{~mm}$. This is because the Poisson's ratio of aluminum tube was larger than that of concrete at the beginning, which led to the lateral expansion of aluminum tube larger than that of core concrete, so there was no contact stress between them. With the increase of the axial deformation, concrete in the core area had cracks and obvious transverse plastic deformation. This made the Poisson's ratio of core concrete increased and exceeded that of aluminum, so that the interaction between aluminum tube and core concrete increased gradually. However, the performance of square CFAT was totally different from that of circular CFAT. Point $\mathrm{A}^{\prime}$ and $\mathrm{C}^{\prime}$ were in expansion area of aluminum tube, and contact stress of point $\mathrm{A}^{\prime}$ and $\mathrm{C}^{\prime}$ did not exist until the axial deformation reached $8 \mathrm{~mm}$, and then aluminum tube lost contact with concrete due to the expansion of aluminum tube. Point B' had contact stress at the beginning and the contact stress increased rapidly with axial deformation rose. This phenomenon could be explained by the fact that point $\mathrm{B}^{\prime}$ located in the corner region. Then a declining segment appeared, which was because that core concrete had entered the stage of elastic-plastic deformation. Point D' was located in the area of depression of concrete, and the contact pressure gradually increased after local buckling of aluminum tube.

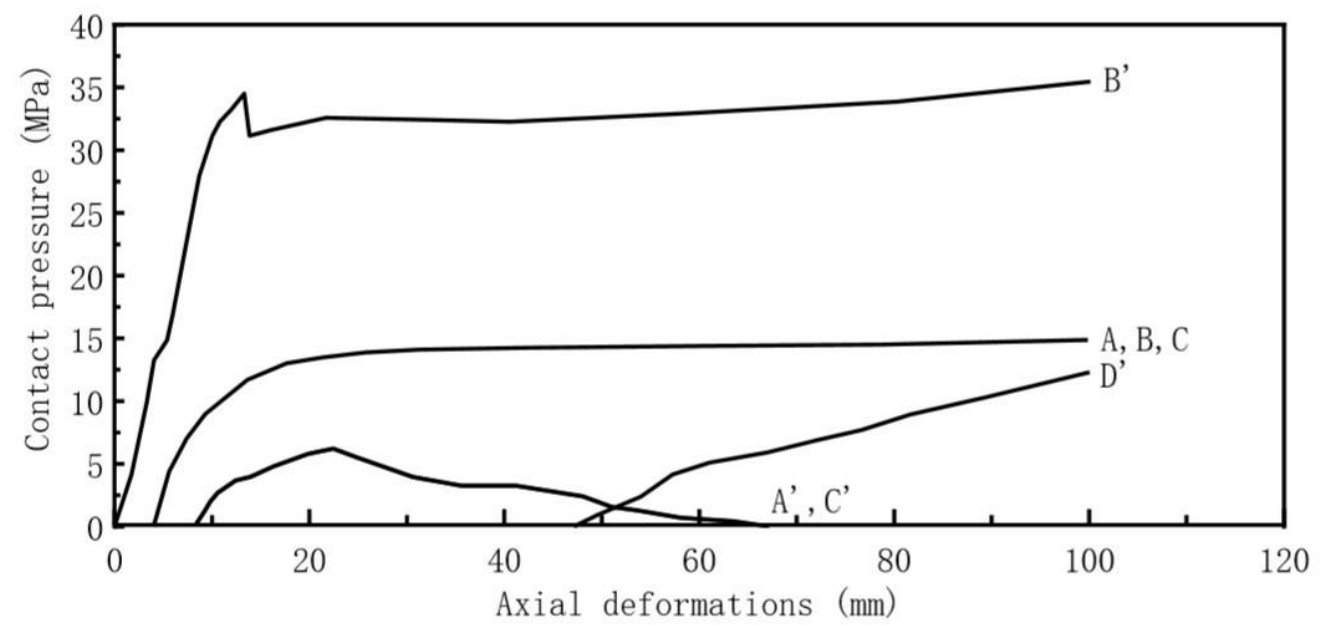

Figure 8: Contact stress of circular (A, B, C) and square (A', B', C', D') columns

\section{Analysis of load-deformation bistories}

Load-deformation curves of circular CFAT core concrete, square CFAT core concrete, aluminum tube of circular CFAT and aluminum tube of square CFAT are shown in Fig. 9.

Loading process could be divided into four stages distinctly by analyzing the above graphs:

Stage 1 (Points O-A): Linear elastic region. Two curves of circular CFAT and square CFAT almost coincided. At this stage, both CFATs remained linear elasticity. For circular CFAT, the pressure of core concrete at point A was about $70 \%$ of its peak value strength, while that of square CFAT was about $90 \%$, which showed that square CFAT relied more on concrete at the early stage of loading.

Stage 2 (Points A-B or A- B'): The characteristic of this stage was described as rising load-displacement curves of two CFATs and continuous declined in the slope of the curves. In this stage, microcracks of core concrete developed constantly, which made the Poisson's ratio of concrete exceed that of aluminum tube. At point B or B ', the ultimate strength of two types of aluminum tubes was attained. Because circular section provided more constraint to the core concrete, two CFAT curves deviated incrementally. At the end of this stage, the axial pressure of circular CFAT was 1.3 times that of square CFAT.

Stage 3 (Points B-C or B'- C'): Axial pressure of both circular and square CFATs decreased gradually and axial deformation increased rapidly. Due to circular section's strong constraint on the core concrete, the reduction of curve of circular CFAT was less than that of square CFAT, and the process of circular CFAT in this stage was significantly longer than that of square CFAT. At point $C$ or $C$ ', the curves of both CFATs reached a low valley. At the end of this stage, the axial pressure of circular CFAT was 1.5 times that of square CFAT. It is indicated that the average slope of the curve at this stage can indirectly represent the ductility of CFAT, which is similarly described by ductility index (DI) in Zhao and Han's study [8]. The smaller the slope is, the worse the ductility is. 
Stage 4 (Points C-D or C'-D'): Because the thickness of the aluminum tube was large enough, these two curves grew steady and slowly, which indicated that circular and square CFATs had good ductility. Finally, the axial pressure of circular CFAT was 1.6 times that of square CFAT.

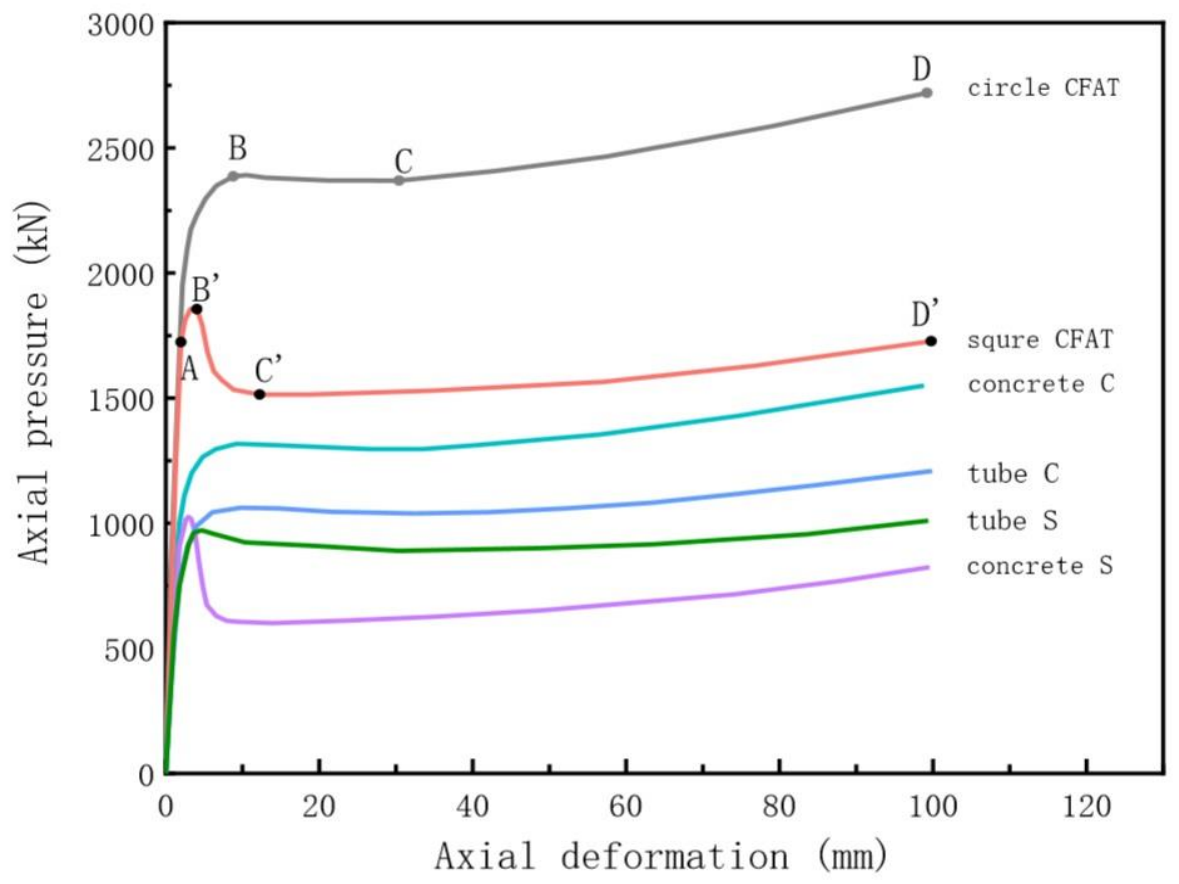

Figure 9: Axial pressure-deformation curves of circular and square CFAT

It was found that the ultimate bearing capacity of circular CFAT was higher than that of square CFAT in the analysis of these four stages and circular CFAT had a better performance than square CFAT in restraining the core concrete. One main reason is that the contact stress distribution of circular CFAT is more uniform, which makes its core concrete under triaxial compression and the constraint effect of aluminum tube gets better. However, the core concrete of square CFAT is under complex stress state. Therefore, the above differences result in different performances of circular CFAT and square CFAT.

\section{PARAMETER ANALYSis}

C omparative parameters adopted in this paper were: core concrete strength, $0.2 \%$ proof stress of aluminum tube and aluminum ratio. In order to better compare the difference between circular CFAT and square CFAT, a parameter named pressure ratio $(\lambda)$ was defined. $\lambda$ can be calculated by the following formula: $\lambda=F_{C} / F_{S}$, where $F_{C}$ is the axial pressure of circular and $F_{S}$ is the axial pressure of square CFAT. Pressure ratio $\lambda$ of standard line represents that the axial pressure of the two CFATs is the same. It is obvious that the closer the curve is to the standard line, the more similar the mechanical properties of two kinds of CFATs are.

\section{Core concrete strength}

Different mechanical performance of circular and square CFATs under axial compression caused by the change of core concrete strength is shown in Fig. 10 and Fig. 11. With the increase of concrete strength, ultimate compressive strength of both CFATs increased, but the slope of the third segment of this curve became smaller, which meant the ductility decreased. In Fig. 12, with the increase of core concrete strength, $\lambda$-D curve was gradually close to the standard line, which meant that the performance of the two CFATs tended to be the same. This phenomenon was explained by the fact that the brittleness of concrete increased when compressive strength rose. Hence the ductility of circular CFAT decreased and became a component with certain brittleness like square CFAT. 


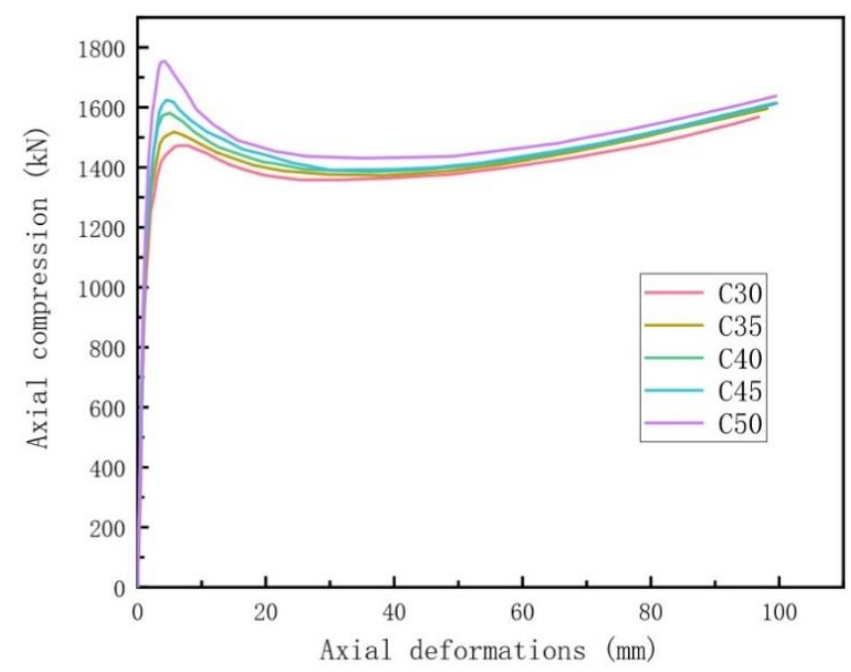

Figure 10: Influence of concrete strength on load-deformation curve of circular CFAT

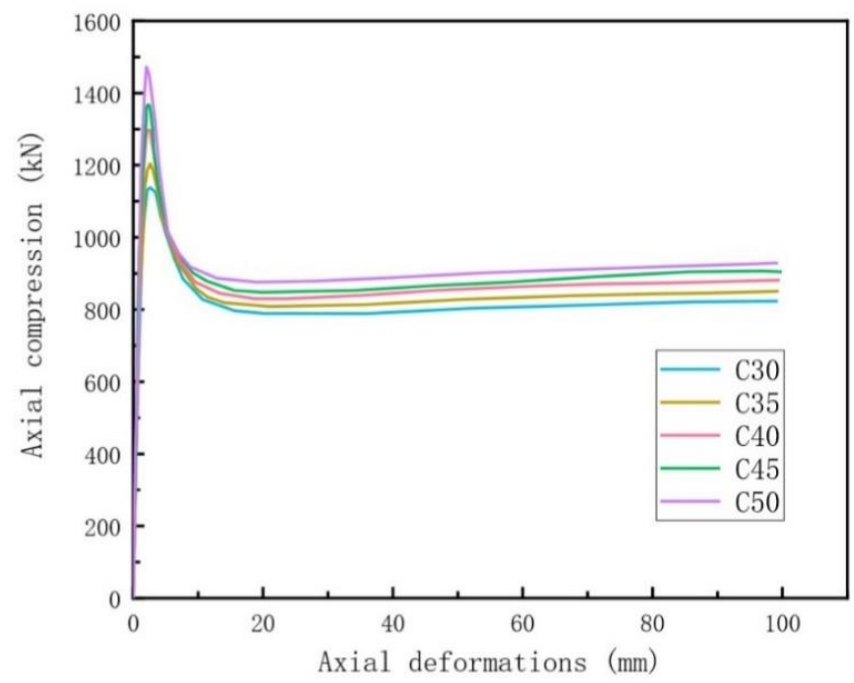

Figure 11: Influence of concrete strength on load-deformation curve of square CFAT

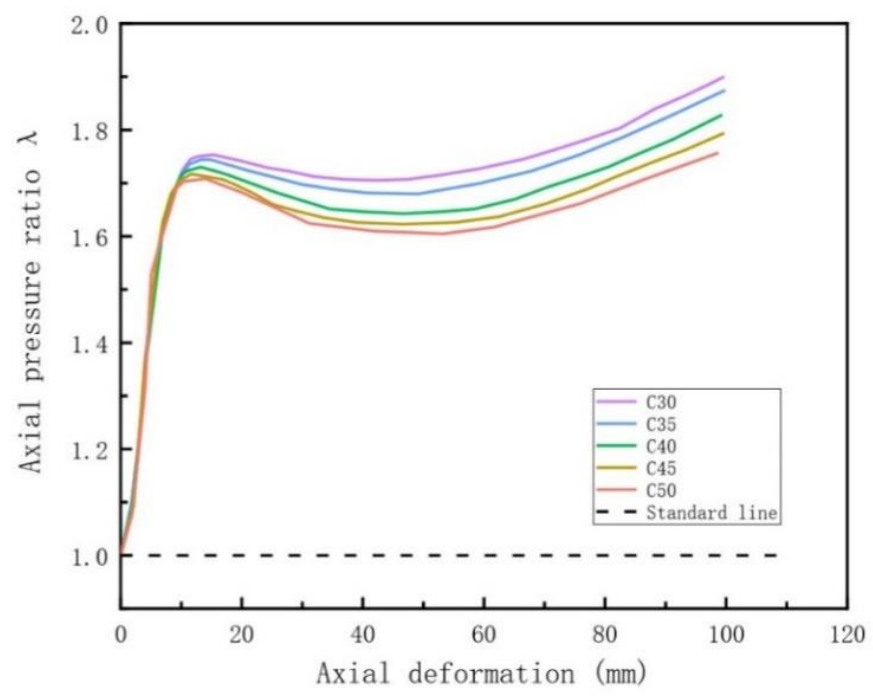

Figure 12: Influence of concrete strength on $\lambda$-D curve 


\section{$0.2 \%$ proof stress of aluminum}

Aluminum is a kind of non-linear material without a sharply defined yield point [7], so the universally accepted method of adopting the stress at $0.2 \%$ plastic strain $\left(0.2 \%\right.$ proof stress $\left.\sigma_{0.2}\right)$ was used here. Several common kinds of aluminum materials were used for this simulation experiment: 5083/T6, 6063/T6, 6082/T6 and 7020/T6. According to GB/T 3880.22012 [19], material specifications ( $0.2 \%$ proof stress and ultimate strength) of these kinds of aluminum are shown in Tab. 2. Under ideal condition, elastic modulus of the above aluminum is $70 \mathrm{GPa}$ and Poisson's ratio is 0.34 . It is noteworthy that the $0.2 \%$ proof stress increases in this order: $5083 / \mathrm{T} 6,6063 / \mathrm{T} 6,6082 / \mathrm{T} 6$ and 7020/T6.

The transformations of mechanical properties under axial compression of two CFATs due to the change of $0.2 \%$ proof stress of aluminum are shown in Fig. 13 and Fig. 14. With the increase of the $0.2 \%$ proof stress of the aluminum, the ultimate compressive strength of these two CFATs increased, while descent segment of the third stage of the curve decreased or even disappeared. The $\lambda$ - $\mathrm{D}$ curve was closer to the standard line with the increase of $\sigma_{0.2}$. This phenomenon shows that with the increase of $\sigma_{0.2}$, the performance of two CFATs gets closer, and the ductility is also improved.

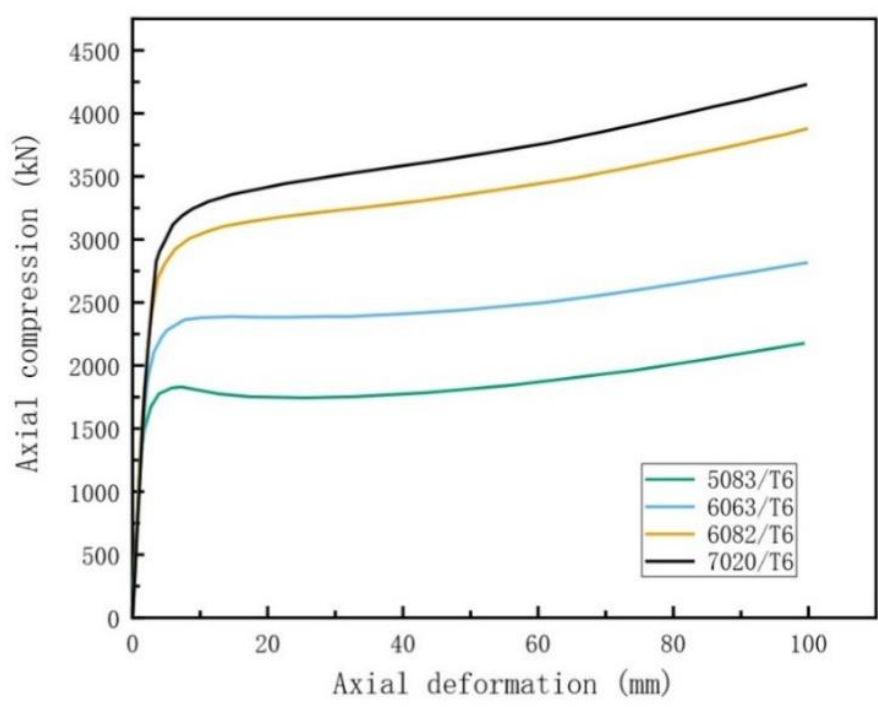

Figure 13: Influence of $\sigma_{0.2}$ on load-deformation curve of circular CFAT

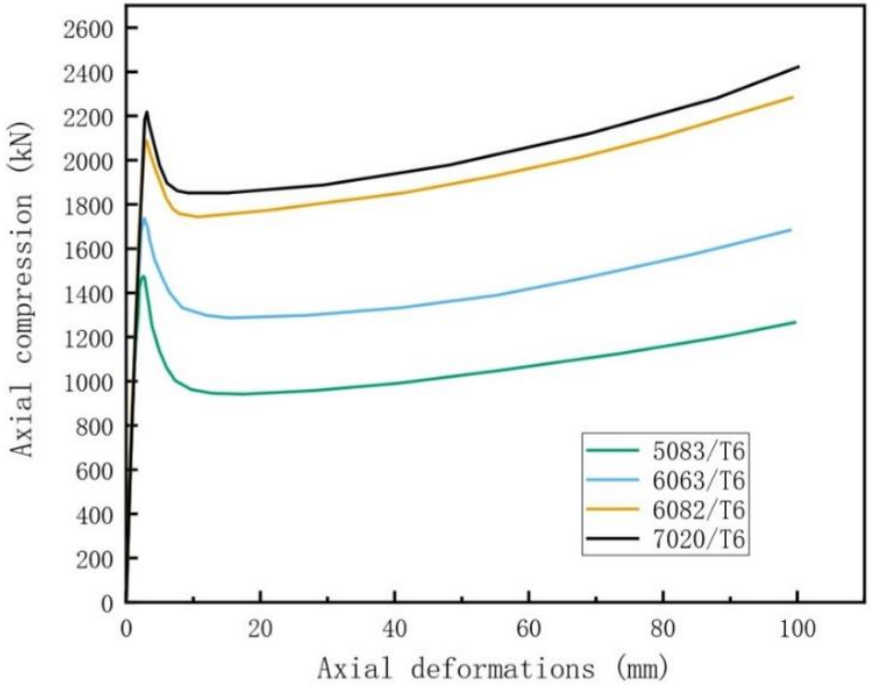

Figure 14: Influence of $\sigma_{0.2}$ on load-deformation curve of square CFAT

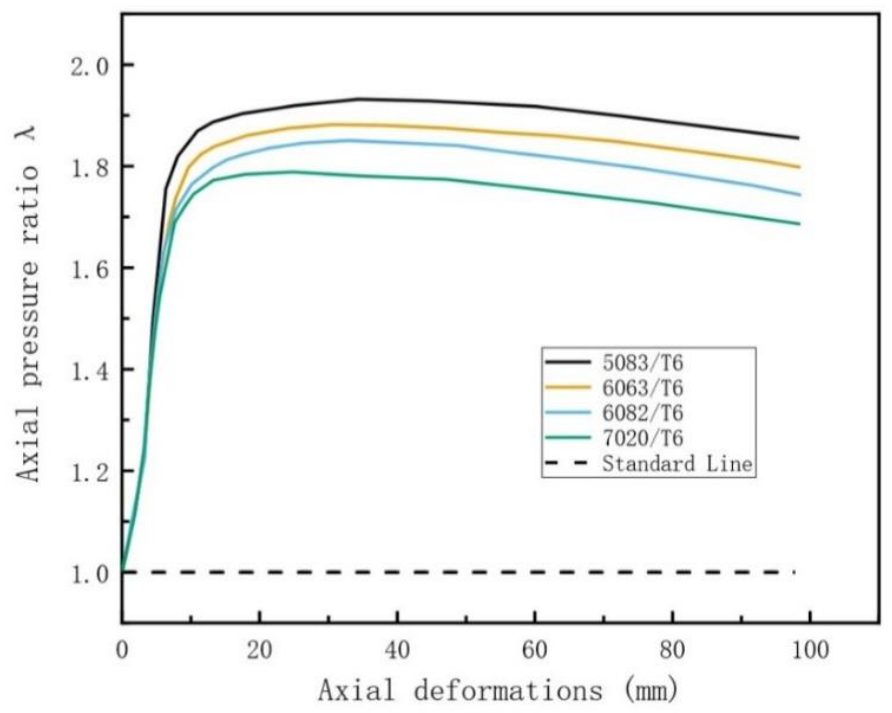

Figure 15: Influence of $\sigma_{0.2}$ on $\lambda$-D curve 


\begin{tabular}{c|cc|cc|cc|c}
\hline Type & \multicolumn{2}{|c|}{$5083 / \mathrm{T} 6$} & \multicolumn{2}{|c|}{$6063 / \mathrm{T} 6$} & \multicolumn{2}{c}{$6082 / \mathrm{T} 6$} & $7020 / \mathrm{T} 6$ \\
$\mathrm{~T}(\mathrm{~mm})$ & $6.0 \sim 12.5$ & $12.5 \sim 40.0$ & $0.5 \sim 5.0$ & $5.0 \sim 20.0$ & $0.14 \sim 6.0$ & $6.0 \sim 22.5$ & $1.5 \sim 40.0$ \\
$\sigma_{0.2}(\mathrm{MPa})$ & 125 & 125 & 190 & 150 & 260 & 255 & 280 \\
$\sigma_{u}(\mathrm{MPa})$ & 275 & 275 & 240 & 230 & 310 & 300 & 350 \\
\hline
\end{tabular}

Table 2: Material specifications of aluminum used in numerical analysis (sign convention is the same as Tab. 1).

\section{Aluminum ratio}

A significant parameter named Aluminum ratio $(\alpha)$ was defined by $\alpha=A_{A} / A_{C}$, where $A_{A}$ was the cross-section area of aluminum tube, $A_{C}$ was the cross-section area of concrete. As shown in Fig. 16 and Fig. 17, with the increase of $\alpha$, the ultimate bearing capacity of circular and square CFAT increased, and the slope of the third stage of the curves gradually increased too, which indicated an increase in ductility. $\lambda$-D curves kept approaching the standard line with the increase of $\alpha$, showing that the increase of $\alpha$ made the performance of two CFATs closer, as shown in Fig. 18. In addition, it is worth noting that according to the four-stage theory mentioned above, the performance of circular CFAT with low $\alpha$ is close to that of square CFAT; while the performance of square CFAT with high $\alpha$ is close to that of circular CFAT. The inspiration for us is that increasing aluminum ratio can improve the ultimate bearing capacity of CFAT and reduce its brittleness in design of CFAT component.

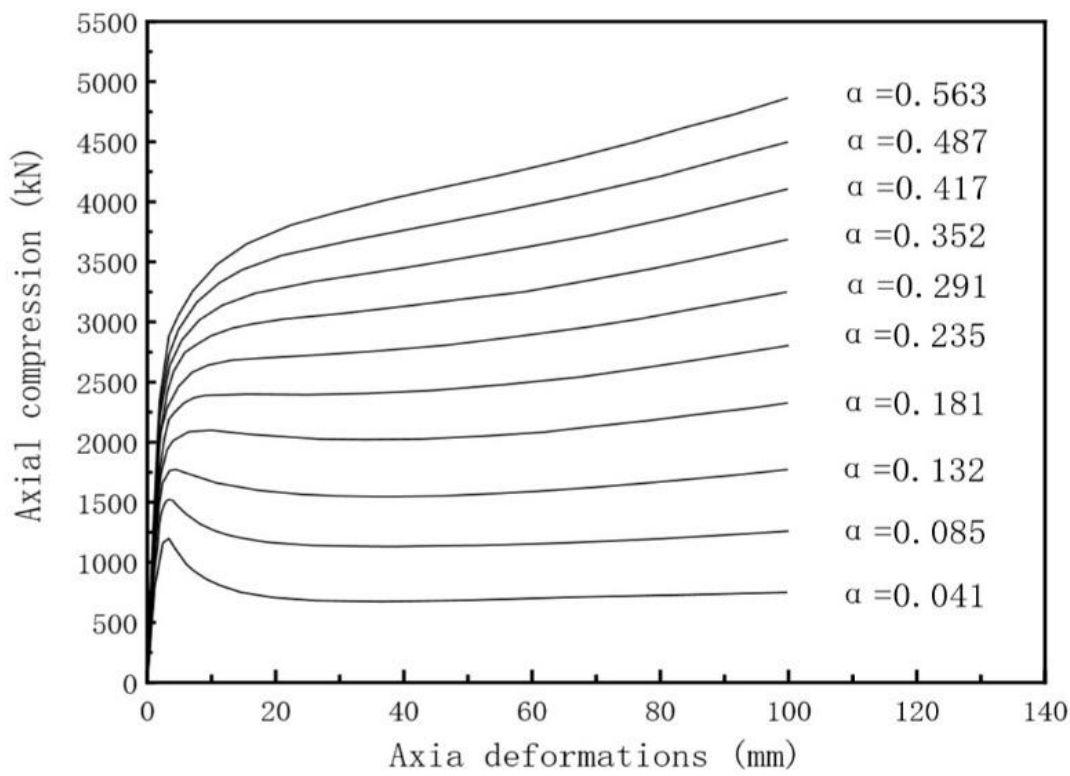

Figure 16: Influence of $\alpha$ on load-deformation curve of circular CFAT

\section{CONCLUSIONS}

B ased on the above results, the following conclusions are drawn:

(1) Finite element models of circular and square CFATs were established. Considering interaction between core concrete and aluminum tube as well as material nonlinearity, simulation values were basically consistent with experimental results.

(2) Study on interaction characteristics between aluminum tube and core concrete was conducted. It is found that the contact pressures between core concrete and aluminum tube of circular and square section CFATs with the same materials have different behavior. The local contact pressure of square CFAT is higher than that of circular CFAT, and the core concrete is under complex stress state. The contact pressure distribution of circular CFAT tube is more uniform. 


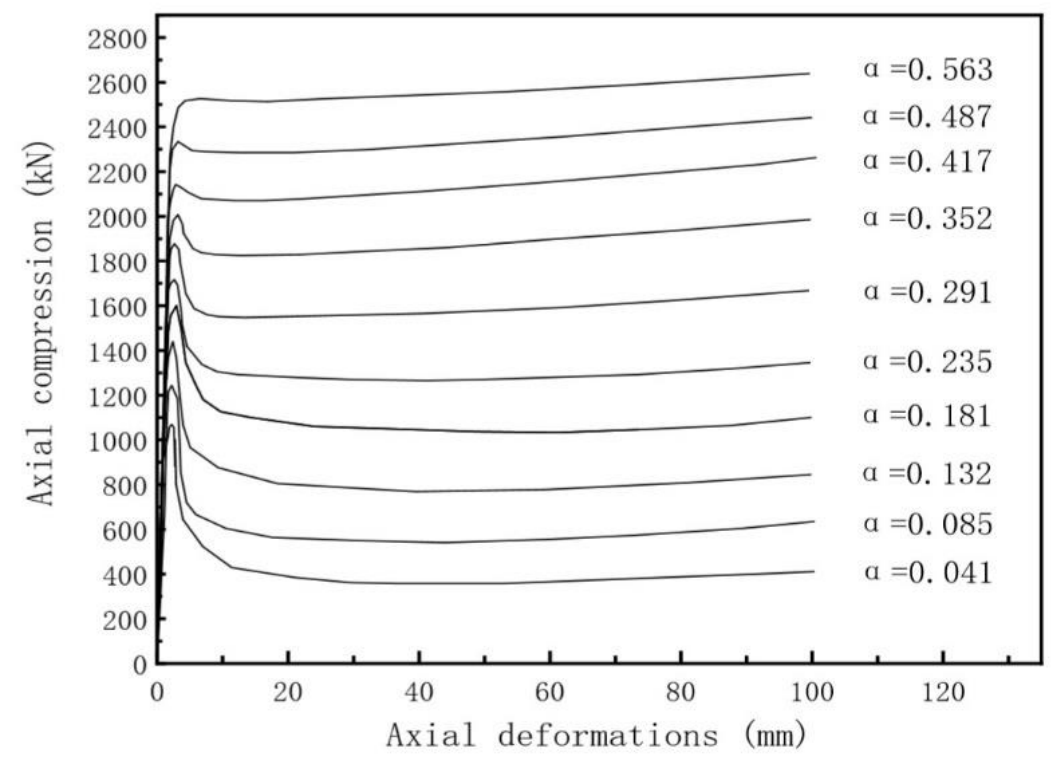

Figure 17: Influence of $\alpha$ on load-deformation curve of square CFAT

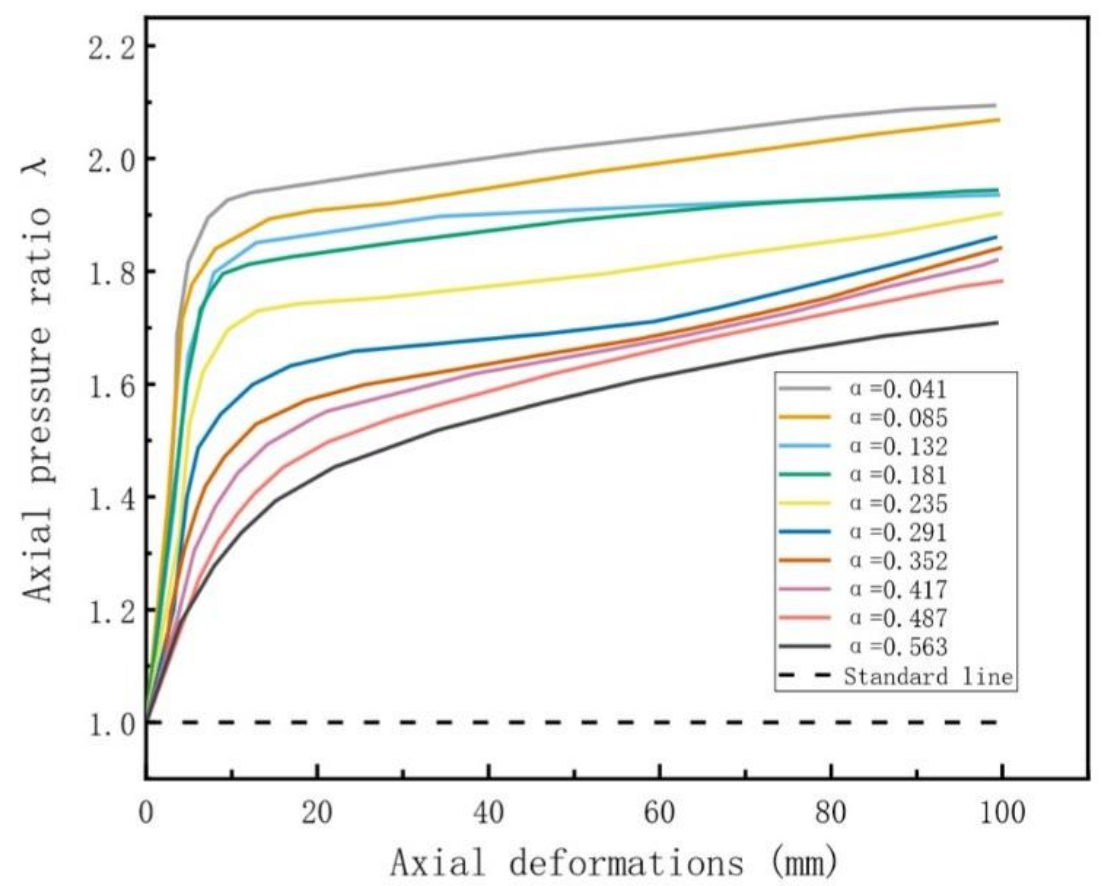

Figure 18: Influence of $\alpha$ on $\lambda$-D curve

(3) Axial compression-deformation curves of different part of circular and square CFATs were analyzed. Four stages exist in axial compression-deformation curves of circular and square CFATs. It is apparent that the aluminum tubes of circular and square CFATs have similar characteristic of mechanical stage, but core concrete of two kinds of CFATs performance differently.

(4) Influence of three parameters (core concrete strength, $0.2 \%$ proof stress of aluminum tube and aluminum ratio) on performance difference of circular and square section CFATs was investigated. It is indicated that the ultimate strength and ductility of these two kinds of CFATs increase as the increasing of either $0.2 \%$ proof stress of aluminum tube or aluminum ratio. With the increase of concrete strength, ultimate strength of circular and square CFATs increase, while the ductility decreases at the same time. 
(5) In the aspect of improving the ductility of CFAT, it is more effective to increase the aluminum ratio than to increase the $0.2 \%$ proof stress of aluminum or reduce the strength of concrete. Increasing aluminum ratio not only changes the ultimate bearing capacity of square and circular CFATs, but also changes the third stage of load-displacement curves, even makes the slope of the third stage change from negative to positive, which means ductility has been greatly improved. However, the other two parameters have less influence on the third stage.

(6) Aluminum ratio has more influence on the difference between circular and square CFAT. The variation range of $\lambda$-D curve peak of concrete strength is $1.72 \sim 1.90$ under the same aluminum ratio, and the variation range of $\lambda$-D curve peak of aluminum strength under the same aluminum ratio is 1.78 1.92. However, under the same concrete strength and aluminum strength, a wider range of 1.70 2.09 can be obtained by changing aluminum ratio.

\section{REFERENCES}

[1] Han, L.H., Li, W., Bjorhovde, R. (2014). Developments and advanced applications of concrete-filled steel tubular (CFST) structures: Members, J. Constr. Steel Res., 100, pp. 211-228, DOI: 10.1016/j.jcsr.2014.04.016.

[2] Su, M.N., Young, B., Gardner, L. (2016). The continuous strength method for the design of aluminium alloy structural elements, Eng. Struct., 122, pp. 338-348, DOI: 10.1016/j.engstruct.2016.04.040.

[3] European Committee for Standardization (EC9). (2007). EN 1999-1-1:2007, Design of aluminum structures-General structure rules, Brussels, CEN.

[4] Zhou, F., Young, B. (2012). Numerical analysis and design of concrete-filled aluminum circular hollow section columns, Thin-Walled Struct., 50(1), pp. 45-55, DOI: 10.1016/j.tws.2011.10.002.

[5] Zhou, F., Young, B. (2009). Concrete-filled aluminum circular hollow section column tests, Thin-Walled Struct., 47(11), pp. 1272-1280, DOI: 10.1016/j.tws.2009.03.014.

[6] Zhou, F., Young, B. (2008). Tests of concrete-filled aluminum stub columns, Thin-Walled Struct., 46(6), pp. 573-583, DOI: $10.1016 /$ j.tws.2008.01.003.

[7] Gardner, L., Ashraf, M. (2006). Structural design for non-linear metallic materials, Eng. Struct., 28(6), pp. 926-934, DOI: $10.1016 /$ j.engstruct.2005.11.001.

[8] Wang, F.C., Zhao, H.Y., Han, L.H. (2019). Analytical behavior of concrete-filled aluminum tubular stub columns under axial compression, Thin-Walled Struct., 140(August 2018), pp. 21-30, DOI: 10.1016/j.tws.2019.03.019.

[9] Su, M.N., Young, B., Gardner, L. (2014). Testing and Design of Aluminum Alloy Cross Sections in Compression, J. Struct. Eng., 140(9), DOI: 10.1061/(asce)st.1943-541x.0000972.

[10] Wang, F.C., Han, L.H. (2019). Analytical behavior of carbon steel-concrete-stainless steel double-skin tube (DST) used in submarine pipeline structure, Mar. Struct., 63, pp. 99-116, DOI: 10.1016/j.marstruc.2018.09.001.

[11] Han, L.H., Yao, G.H., Tao, Z. (2007). Performance of concrete-filled thin-walled steel tubes under pure torsion, ThinWalled Struct., 45(1), pp. 24-36, DOI: 10.1016/j.tws.2007.01.008.

[12] L. Han. (2016). Concrete Filled Steel Tubular Structures-Theory and Practice, Third (In Chinese), Beijing, China Science Publishing \& Media Ltd.

[13] American Concrete Institute. (2011). Building Code Requirements for Structural Concrete (ACI 318-11) and Commentary, Farmington Hills, MI. DOI: 10.1016/0262-5075(85)900326.

[14] ABAQUS. (2014). ABAQUS Standard User's Manual, Version 6.14, Dassault Systemes Corp., Providence, RI (USA).

[15] Schneider, S.P. (1999). Axially loaded concrete-filled steel tubes - Closure, J. Struct. Eng., 125(10), pp. 1206, DOI: 10.1061/(ASCE)0733-9445(1999)125:10(1206.x).

[16] American Society for Testing and Materials. (1997). Standard test methods for tension testing of metallic materials (E 8M-97), West Conshohocken, USA

[17] American Concrete Institute. (1995). Building code requirements for structure concrete and commentary (ACI 318-95), Detroit, USA

[18] China MOC. (2010). Code for design of concrete structures, Beijing, China Construction Industry Publishing House.

[19] China's General Administration of Quality Supervision (AQSIQ). (2012). Wrought aluminium and aluminium alloy plates, sheet and strips for general engineering-Part 2: Mechanical properties, Bejing, National Standardization Administration of China 